\title{
Non-factual Before and Adverbs of Quantification
}

\author{
Toshiyuki Ogihara \\ University of Washington
}

\begin{abstract}
This article discusses the semantics of before, with special reference to socalled non-factual before and its interaction with adverbs of quantification. I will adopt a version of Anscombe's (1964) analysis of before and supplement it with a modal-temporal presupposition lexically induced by before. This account will be extended to quantificational cases as well within Rooth's (1985) theory of association with focus. Distinct interpretations associated with so-called factual and non-factual before-clauses are explained in terms of pragmatic presuppositions.
\end{abstract}

\section{Introduction}

An asymmetry between before and after has been noted by many researchers. Heinämäki $(1972,1974)$ presents some examples that clearly illustrate the difference.

(1) a. John died before he saw his grandchildren.

b. Harry put money in the parking meter before a policeman gave him a ticket.

(1a) does not entail that John saw his grandchildren. On the contrary, we tend to infer from it that he did not. (1b) makes the same point: its default reading is that Harry did not get a ticket because he put money in the parking meter. Although these inferences are context-dependent, one thing is clear: the truth of the entire sentence does not guarantee the truth of the before-clause it contains. Let us tentatively refer to the occurrences of before-clauses in (1a-b) on their default interpretations non-factual before-clauses. In this paper, I will use the term "nonfactual" to refer to a before-clause that is not entailed by the sentence in which it is embedded. ${ }^{1}$ It is prima facie justifiable to make a stronger claim here because (1a) (or (1b)) appears to entail the negation of the before-clause that it contains. However, since I argue later that a pragmatic presupposition is responsible for this inference, I refrain from making a stronger claim here. When a before-clause appears to be entailed or presupposed by the sentence that contains it, I will refer to it as a factual before-clause. I will discuss alleged factual before-clauses below.

By contrast, after behaves in a different way. Consider the following:

(2) a. John saw his grandchildren after he died.

b. A policeman gave him a ticket after Harry put money in the parking meter.

(2a) sounds contradictory. This is because it entails (and perhaps presupposes) the truth of the after-clause, which is impossible as we normally assume that two people can see each other only when they are both alive. (2b) also sounds odd, and we must imagine an unusual situation to make sense of it. One possible scenario is that Harry got a ticket because the policeman made an error. Assuming that both the main clause and the after-clause induce existential quantification over times, we can translate (2a) as in (3). ${ }^{2}$ 

at $\left.t^{\prime}\right]$

(3) does not account for the meaning of (1a), however. Intuitively, (1a) is true in a circumstance where John dies without having a chance to see his grandchildren. For example, John dies when his daughter, who is his only child, is pregnant with her first child.

Some instances of before-clauses are strongly biased toward either factual or non-factual readings. As mentioned above, the before-clauses in (1a-b) are interpreted in normal circumstances as non-factual before-clauses. In fact, it is pragmatically impossible for each before-clause to be true if the main clause is true. On the other hand, example (4) due to Heinämäki (1972) seems to entail the before-clause.

Sachi bought a Toyota before the price went up.

If this observation is correct, (4) provides an instance of factual before. In other cases, the two distinct interpretations of the before-clause are readily available and are equally plausible.

John pushed the button before the fire started.

When (5) is true, the before-clause can be either true or false depending upon the context. Suppose that pushing the button causes a fire to start. Then it seems to entail that the fire did in fact start. On the other hand, it is possible to assume that pushing the button activates a mechanism that prevents a fire. On this assumption, (5) seem to entail that the fire did not start. Thus, if the distinction between factual before and non-factual before is warranted, the distinction must be made in reference to before-clauses used in specific contexts.

Another important difference between before and after is that beforeclauses, but not after-clauses, license negative polarity items (Heinämäki (1974), Landman (1991)).
a. John read the book before anyone else ever did.

b. * John read the book after anyone else ever did.

Any successful proposal must account for the above facts about before.

Note also that this asymmetry between before and after is also found in other languages. For example, Japanese exhibits the following contrast between mae-ni 'before' and ato-de 'after':
a. Taroo-wa mago-no
Taro-TOP grandchild
kao-o min mae-ni sin-da. Taro-TOP grandchild-GEN face-ACC see-PRES before die-PAST 'Taro died before he saw his grandchildren.'
b. Taroo-wa sin-da ato-de mago-no kao-o mi-ta. Taro-TOP die-PAST after grandchild-GEN face-ACC see-PAST 'Taro saw his grandchildren after he died.'

$(7 a-b)$ are completely parallel to (1a) and (2a), except that mae-ni-clauses ('before-clauses') in Japanese are always in the present tense (Ota 1973, Nakau 1976, Ogihara 1994). ${ }^{3}$ This fact shows that the asymmetry between before and after is not a language-specific fact and is relevant to general linguistic theory. 


\section{Anscombe's Analysis of Before}

Anscombe (1964) presents an analysis of the semantics of before-clauses on the basis of the English data that involve factual before. Her argument is based upon stative sentences like the following:

(8) a. The Parthenon was there before St. Peter's was there.

b. St. Peter's was there before the Parthenon was there.

c. St. Peter's was there after the Parthenon was there.

d. The Parthenon was there after St. Peter's was there.

Assume the history of the two buildings described by a diagram in (9).

(9)

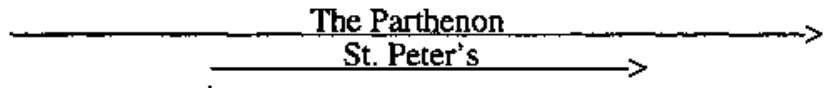

Anscombe observes that (8a) and (8b) cannot be both true, whereas (8c) and (8d) can be. For example, in (9), the Parthenon was erected earlier than St. Peter's and was there after St. Peter's was torn down. In this circumstance, (8a) and (8c-d) are true, but ( $8 \mathrm{~b})$ is false. In order to account for the difference between before and after attested by the examples in (8), Anscombe suggests as one possible analysis the following truth conditions for a past tense sentence that contains a before-clause: 4

(10) A sentence of the form $p$ before $q$, where $p$ and $q$ are sentences in the past tense, is true iff the following condition holds: $\exists t\left[t<\right.$ now $\wedge p^{\prime}$ is true at $t$ $\wedge \forall t^{\prime}\left[\left[t<\right.\right.$ now $\wedge q^{\prime}$ is true at $\left.\left.\left.t^{\prime}\right] \rightarrow t<t^{\prime}\right]\right]$, where $p^{\prime}$ and $q^{\prime}$ are tenseless forms of $p$ and $q$, respectively.

According to (10), (8a) is true iff there is a past time $t$ such that the Parthenon exists at $t$ and any past time $t^{\prime}$ at which St. Peter's exists follows $t$. The circumstance described in (9) verifies this condition. On the other hand, (8b) is false with respect to (9) because there is no time at which St. Peter's exists and with respect to which the Parthenon's existence is wholly in the future. Thus, (10) successfully accounts for the difference between (8a) a d (8b). ${ }^{5}$ This proposal is adopted in essentially the same form by Heinämäki (1972) and by Landman (1991).

(10) has two advantages over (3). First, although (10) is not based upon non-factual before-examples, it accounts for them as well as for factual cases. According to (10), a sentence of the form $p$ before $q$ does not entail the beforeclause. It says: if there is a past time at which the before-clause is true, then it must be located after the main clause episode. This condition is satisfied by both factual before and non-factual before, if we disregard the possibility for the moment that repeatable events are involved. If a before-clause event occurs after a main-clause event, then (10) is satisfied. If there is no before-clause event, (10) is vacuously satisfied. 6 Thus the truth conditions given in (10) provide a unified account of before-clauses. 7

Second, as Landman (1991) shows, (10) predicts that a before-clause is a downward entailing context. This can be demonstrated by replacing a beforeclause with one that entails the before-clause.

a. $\quad$ Mary left. $\Rightarrow$ Mary or Sue left.

b. John left before Mary or Sue left. $\Rightarrow$ John left before Mary left.

Let the first sentence in (11b) be true. Then the formula given in (12) is true: 
Let $t_{0}$ be a past time at which John leaves. Then the truth condition for the before-clause is satisfied iff $\{t \mid t<$ now and Mary or Sue leaves at $t\} \subseteq\{t \mid$ $\left.t_{0}<t\right\}$. Given the standard assumptions about the semantics of disjunction, the following condition holds: $\{t \mid t<$ now and Mary leaves at $t\} \subseteq\{t \mid t<$ now and Mary or Sue leaves at $t\}$. It is now clear that $\{t \mid t<$ now and Mary leaves at $t\} \subseteq$ $\left\{t \mid t_{0}<t\right\}$. This means that the formula given in (13) is true.

$$
\begin{aligned}
& \exists t[t<\text { now } \\
& \left.\left.t<t^{\prime}\right]\right]
\end{aligned}
$$

Note that Anscombe's semantics for before translates (11b) as (13). This shows that a before-clause is a downward-entailing context, according to the truth conditions given in (10). This is also nice because as we saw above, negative polarity items can occur in before-clauses but not in after-clauses, and Ladusaw (1979) shows independently that negative polarity items can only occur in downward entailing contexts. 8

Let me make one cautionary remark about Anscombe's analysis. The difference between before and after cannot be established by using stative predicates in Japanese. Japanese does not permit stative before-clauses as in (14ab), whereas (14c), which has a stative main clause predicate, is perfectly acceptable.

$$
\begin{aligned}
& \text { a. * Taroo-wa kenkyuusitu-ni iru mae-ni, tenisu-o si -ta. } \\
& \text { Taro-TOP office-at be-PRES before tennis-ACC do-PAST } \\
& \text { [intended] 'Taro played tennis before he was in his office.' } \\
& \text { b. * Taroo-wa kenkyuusitu-ni iru mae-ni, } \\
& \text { Taro-TOP office-at be-PRES before } \\
& \text { tenisu kooto-ni i-ta. } \\
& \text { tennis court-at be-PAST } \\
& \text { c. } \\
& \text { Taronded] 'Taro was on the tennis court before he was in his office.' } \\
& \text { Taro-TOP tennisu-A suru mae-ni kenkyuusitu-ni i-ta. } \\
& \text { 'Taro was in his office before he played tennis.' }
\end{aligned}
$$

My native informant reports that the English gloss for (14a) sounds odd because the main clause has an event verb whereas the before-clause has a stative verb. In other words, English tends to prefer the main clause and the before-clause to be of the same Aktionsart ('action type'). By contrast, the Japanese sentence in (14a) is ungrammatical simply because the before-clause has a stative predicate. This is shown by (14b), which has a stative predicate in both clauses. It is as anomalous as (14a) though its English gloss is perfectly acceptable. I have no good explanation for this difference between English and Japanese. Since Anscombe's analysis otherwise successfully accounts for the English and Japanese data, I assume for the purpose of this paper that Japanese has an independent and possibly language-specific syntactic constraint on types of verbs that can be used in specific constructions.

I have shown above that Anscombe's analysis accounts for both factual and non-factual readings of before-clauses. What then is responsible for the perceived differences between these two types of interpretation? Let us now turn to Heinämäki $(1972,1974)$, who examines various examples that involve before (given below as (15a-e)) and categorizes them as in (16). 
a. Sachi bought a Toyota before the price went up. (Factual 1)

b. We had to install a new battery before the car started. (Factual 2)

c. John died before he saw his grandchildren. (Non-factual 1)

d. John died two months before he would have retired. (Non-factual 2)

e. I left the country before anything happened. (Non-committal)

Two comments are in order here. First, Heinämäki notices that in some cases the speaker does not commit himself to the truth or falsity of a before-clause, as in (15d). She uses the term "non-factual before" to designate a before-clause that is perceived to be false and reserves the term "non-committal" for cases where the truth value of the before-clause is left open. Second, non-factual before (in Heinämäki's terms) requires that there be a causal connection between the main clause event and the negation of the before-clause event. This seems to show that a before-clause describes an event that is assumed to obtain unless something prevents its occurrence. Let us discuss these two points in more detail.

Characteristic

1. before-clause is true

2. takes modifiers such as just, right, and temporal measure phrases

3. causal relation between the clauses

a. main clause prevents

the before-clause

b. main clause makes

the before-clause possible
Type of before-clause

factual non-factual non-committal $\begin{array}{lllll}1 & 2 & 1 & 2\end{array}$

yes yes no no not known

yes no no yes no

no yes yes yes no

- no yes yes -

- yes no no

Consider (17), which is another example of non-committal before (in Heinämäki's terms).

(17) John attended a party held at Bill's house. Bill drank a lot and looked as if he was going to get drunk. Since John hates to deal with drunkards, he left before Bill got drunk.

The italicized sentence in (17) leaves open whether Bill actually got drunk after John left. If we assume that John's leaving has nothing to do with whether Bill actually gets drunk later, the two possible outcomes do not seem to require two different interpretations of the sentence. Seen from John's perspective, what he did was to leave while Bill was still not drunk. This type of paraphrase is quite natural and common in Japanese.
a. Zyon-wa Biru-ga yopparau mae ni kaet-ta. John-TOP Bill-NOM get-drunk before at leave-PAST 'John left before Bill got drunk.'
b. Zyon-wa Biru-ga yopparawa-nai uti-ni kaet-ta. John-TOP Bill-NOM get-drunk-NEG while-at leave-PAST [Lit.] 'John left while Bill does not get drunk.'9

(18a) and (18b) convey approximately the same information, and the latter shows clearly that the temporal information conveyed is that of Bill's leaving at a time when the before-clause event has not (yet) obtained. Something similar is possible 
in English. The last sentence in the discourse given in (17) can be paraphrased as in (19), which conveys approximately the same information as the Japanese example given in (18b).

John left while Bill was still not drunk.

I take the semantic equivalence between (18a) and (18b) (or between the italicized sentence in (17) and (19)) to be an important piece of evidence for Anscombe's analysis of before-clauses because the translation of (18a) based upon (10) can be converted into a formula that is intuitively the right translation for (18b).

$$
\begin{aligned}
& \exists t\left[t<\text { now } \wedge p^{\prime} \text { is true at } t \wedge \forall t^{\prime}\left[\left[t^{\prime}<\text { now } \wedge q^{\prime} \text { is true at } t^{\prime}\right] \rightarrow t<t^{\prime}\right]\right] \\
& \exists t\left[t<\text { now } \wedge p^{\prime} \text { is true at } t \wedge \forall t^{\prime}\left[\neg\left[t^{\prime}<\text { now } \wedge q^{\prime} \text { is true at } t^{\prime}\right] \vee t<t^{\prime}\right]\right] \\
& \text { [conditional law] } \\
& \exists t\left[t<\text { now } \wedge p^{\prime} \text { is true at } t \wedge \forall t^{\prime} \neg\left[\left[t^{\prime}<\text { now } \wedge q^{\prime} \text { is true at } t^{\prime}\right] \wedge \neg\left[t<t^{\prime}\right]\right]\right] \\
& \text { [de Morgan's law] } \\
& \exists t\left[t<\text { now } \wedge p^{\prime} \text { is true at } t \wedge \neg \exists t^{\prime}\left[\left[t^{\prime}<\text { now } \wedge q^{\prime} \text { is true at } t^{\prime}\right] \wedge \neg\left[t<t^{\prime}\right]\right]\right] \\
& {[\text { law of quantifier negation] }} \\
& \exists t\left[t<\text { now } \wedge p^{\prime} \text { is true at } t \wedge \neg \exists t^{\prime}\left[\left[t^{\prime}<\text { now } \wedge q^{\prime} \text { is true at } t^{\prime}\right] \wedge t^{\prime} \leq t\right]\right] \\
& \text { [conversion due to an obvious semantic relation between ' }<\text { ' and ' } \leq \text { '] }
\end{aligned}
$$

The fact that the above intuitively correct semantic equivalence is supported by a logical equivalence shows that Anscombe's analysis is on the right track.

This paraphrase also provides an answer to a conceptual puzzle associated with Anscombe's proposal: why is it that before manages to convey a universal quantifier meaning? The paraphrase given in (20) shows clearly that the meaning of before $q$ should be taken as the negation of after or when $q$. Let us assume that a past tense sentence of the form $p$ TC $q$, where TC is a temporal connective (before, after or when), is used when the hearer wants to know when a $p$ event obtained in relation to a $q$ event, which was likely to occur within the reference time. The focus of attention is whether a $q$ event had already obtained (indicated by after), was obtaining (indicated by when), or had not (yet) obtained (indicated by before) when a $p$ event occurred. In other words, the deictic center is the time of the $p$ event. On this analysis, before is used to deny the existence of an earlier $q$-event or a concurrent $q$ event in relation to the main clause event. My claim then is that before indicates the "complement" of the possibilities suggested by after or when. Note that (21a) translates as (22a), according to the above paraphrase, whereas (21b) translates as (22b). It is clear that (22a) is semantically equivalent to $(22 b)$.

(21) a. John left before Mary got drunk.

b. It was not after Mary got drunk or when she got drunk that John left.

a. $\exists t\left[t<\right.$ now $\wedge$ John leaves at $t \wedge \neg \exists t^{\prime}\left[t^{\prime} \leq t \wedge\right.$ Mary gets drunk at $\left.\left.t^{\prime}\right]\right]$

b. $\exists t\left[t<\right.$ now $\wedge$ John leaves at $t \wedge \neg \exists t^{\prime}\left[t^{\prime}<t \wedge\right.$ Mary gets drunk at $\left.t^{\prime}\right]$ $\wedge \neg[$ Mary gets drunk at $t]]$

Additional evidence for a unified approach to before-clauses comes from Spanish (Antxon Olarrea, personal communication). Both factual and non-factual before clauses are rendered as Spanish sentences in the subjunctive, rather than in the indicative, and there is no overt morphological marker that distinguishes between the two types of before. 


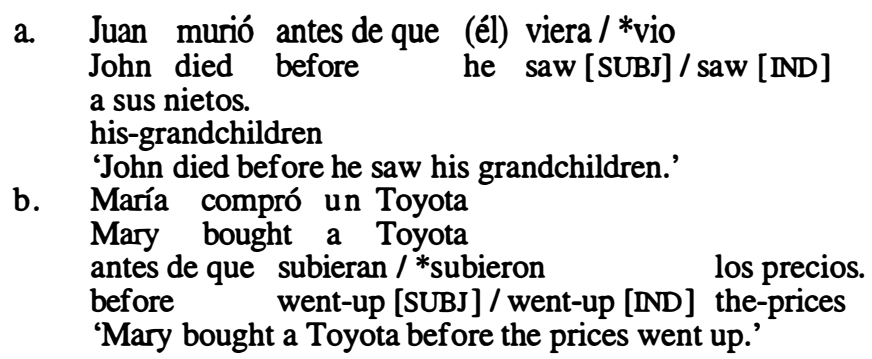

Infinitival verb forms can be used when the subject of the before-clause is the same as that of the main clause, but they do not distinguish between factual before and non-factual before, either.

The examples that we have looked at suggest that Anscombe's analysis given in (10) is on the right track and applies to all attested examples of beforeclauses. The distinct interpretations of before-clauses can be accounted for in terms of presuppositions. For example, if the main clause event is assumed to prevent the before-clause event from taking place as in (1a) $(=(15 \mathrm{c})$ ), it is natural to infer that no before-clause event obtained. If the main clause is assumed to enable the before-clause to be true as in (15b), then it is perceived to be a case of factual before. In Section 5, I will discuss in more detail how to incorporate such presuppositions in my system.

\section{Issues}

The discussion up to here suggests that $(10)$ is the one we need for the truth conditions for sentences that involve a before-clause, regardless of its type. However, some supplementary tools are needed to account for additional readings associated with before-clauses. For example, (10) does not explain why a beforeclause cannot depict an episode that could not possibly have occurred.

The Namibian boy died of starvation before he became the president of the United States.

If it is in fact the case that the Namibian boy died of starvation, then (10) predicts that (24) is true, and it does not explain why (24) sounds very odd. Intuitively, the before-clause must depict a situation that could have occurred around the time of the main clause event, and (24) fails in this respect (partly) because the Namibian boy would never have been able to become president of the United States because only U.S.-born individuals can become president. Needless to say, we are not talking about an absolute possibility here because the relevant clause in the Constitution could be changed, but the point is that when the before-clause is extremely unlikely to be true, the entire sentence tends to be anomalous. This is true of Japanese, too.

It is not enough for the event described by a before-clause to be a probable event. A before-clause must describe something that was likely to obtain in the near future relative to the main clause event. This point is established by examples like (25).

(25) The five-year-old girl died before she saw her grandchildren.

Suppose that her grandchildren refers to the girl's biological grandchildren. Then although the truth conditions given in (10) are satisfied and the girl could have seen her grandchildren had the girl been alive, (25) still sounds very odd. The 
reason seems to be that even if the girl had not died, it would have been some fifty years later that she became a grandmother. Thus, although it would have been likely that there would be a time at which the before-clause was true, such a time would have been much later than the main clause event. Thus, (25) sounds very strange as a result. The same point could be made with (24) as well. example:

This problem is closely related to the one suggested by the following

John went to sleep before he washed his face.

Suppose that John went to bed, had seven hours of sleep, got up, and washed his face. In this situation, (10) predicts that (26) is true. However, (26) sounds odd, if not completely unacceptable. Stump (1985) notices this problem and guarantees the temporal proximity of the main clause event and the before-clause event by positing a pragmatically defined temporal relation, but he only discusses factual before examples there. Since (10) does not guarantee that there is an actual event described by the before-clause, it is technically impossible to specify the temporal distance between the time of the matrix and the time of the before-clause when the before-clause is never true. Examples like (24) through (26) support the idea that a before-clause must describe an event that is very likely to occur around the time of the matrix clause event. I will incorporate this important observation into my proposal, keeping in mind the insight of Anscombe's analysis.

Another problem with Anscombe's original proposal is associated with repeated occurrences of the same type of event. Anscombe herself is aware of this problem. For example, in (27) her proposal given above as (10) works only if there is no before-clause event earlier than the time at which the main clause is true.

John called Mary before he visited her.

However, this prediction does not match our intuitions. (27) could be true even if John visited Mary many times in the past and on the first occasion he visited her without calling her in advance. On this scenario, (10) predicts that (27) is never true because there is no phone call event that precedes every visiting event. Intuitively the source of the problem is clear. In general, a tensed sentence must be evaluated with respect to a contextually salient interval, which is often referred to as a reference time, following Reichenbach (1947). I revise (10) as in (28) by incorporating this aspect of tense meaning.

(28) A sentence of the form $p$ before $q$, where $p$ and $q$ are sentences in the past tense, is true iff the following condition holds: $\exists t\left[t<\right.$ now $\wedge t \subseteq t_{R} \wedge$ $p^{\prime}$ is true at $t \wedge \forall t^{\prime}\left[\left[t^{\prime}<\right.\right.$ now $\wedge t^{\prime} \subseteq t_{R} \wedge q^{\prime}$ is true at $\left.\left.\left.t^{\prime}\right] \rightarrow t<t^{\prime}\right]\right]$ where $p^{\prime}$ and $q^{\prime}$ are tenseless forms of $p$ and $q$, respectively. $t_{R}$ is an indexical that denotes a contextually salient interval.

This is a modification in the right direction. (28) guarantees that when we say that a main clause event occurs at a time after which every before-clause event occurs, we only pay attention to a restricted interval. In addition, non-factual cases show that the occurrence of a before-clause event must be highly likely throughout the reference time in question. Thus, we could incorporate this information into the truth conditions along the following lines: 
p before $q$ is true iff $\exists t\left[t<\right.$ now $\wedge t \subseteq t_{R} \wedge p^{\prime}$ is true at $t \wedge \forall t \llbracket \llbracket t<$ now $\wedge$ $t \subseteq t_{R} \wedge q^{\prime}$ is true at $\left.\left.\left.t\right] \rightarrow t<t\right]\right]$ is true, where $t_{R}$ denotes the contextually salient past interval during which the occurrence of a $q^{\prime}$-type event is very likely.

I believe this is essentially the right approach to the semantics of (both factual and non-factual) before-clauses. The requirement that $t_{R}$ receive as its value an interval during which an occurrence of $q^{\prime}$-type event is likely should be understood as a presupposition, rather than an assertion made by a before-clause. To simplify the treatment of presuppositions, however, I will incorporate it into the translation of before in the following account. Our next task is to make precise the notion of "likely occurrences of some event." Since this clearly involves modal concepts, I will propose a modal-temporal analysis of before-clauses. The idea represented in (29) can be restated in formal terms as in (30).

(30) A sentence of the form $p$ before $q$, where $p$ and $q$ are sentences in the past tense, is true in $w_{0}$ at the speech time $s *$ with respect to some context $c_{Q}$ iff there is a time $t_{1}<s^{*}$ located within the reference time $t_{R}$ at which $p$ is true in $w_{0}$ and there is a time $t_{2}$ that abuts $t_{R}$ and in every world $w \in \operatorname{In} r\left(\left\langle w_{0}, t_{2}\right\rangle\right)$, there is a time $t_{3} \subset t_{R}$ such that $q^{\prime}$ is true in $w$ at $t_{3}$, and every time $t_{4} \subset t_{R}$ at which $q^{\prime}$ is true in $w_{0}$ is located after $t_{1}$. [N.B. For some technical reasons to be made explicit later, the proper-subset symbol ' $C$ ' is used to indicate a non-initial subinterval in this paper. For example, $t_{1} \subset t_{2}$ indicates that $t_{1}$ is a non-initial subinterval of $t_{2}$. Definition: $t_{1} \subset t_{2}$ iff $t_{1} \subseteq t_{2}$ and there is a time $t$ such that $t \subseteq t_{2}$ and $t<t_{1}$.]

$I n r$ is a function from $W \times T$ into $\wp(W)$ (i.e., the power set of the set of worlds) and is introduced by Dowty (1979:148-150) to account for the semantics of the progressive. Intuitively, for any world $w$ and any interval $t, \operatorname{Inr}(\langle w, t>)$ is the set of worlds which are exactly like $w$ up to and including $t$ and in which the future course of events after this time develops in ways most compatible with the past course of events. (30) says that the main clause is true at a time within the contextually determined reference time $t_{R}$, and $q^{\prime}$ is very likely to occur within $t_{R}$. Moreover, $p^{\prime}$ occurs within $t_{R}$ before any occurrence of $q^{\prime}$ within $t_{R}$. This proposal takes care of both factual and non-factual before-clauses.

In the following discussion, I will employ a logical language in which temporal terms appear as arguments of various predicates. I will show in (33) how a sentence of the form $p$ before $q$ translates into $I L$ compositionally, with the help of binary operator DEFAULT as defined in (31) and temporal relation 'abut' as defined in (32). Informally, DEFAULT $(k)(t)$ reads "there is a time within $t$ at which $k$ obtains by default." I follow Dowty (1979) and use $i$ to designate the type for intervals. I will use the symbol " $s$ " to indicate the speech time in the following translations.

DEFAULT is an expression of type $<<i, t>,<i, t>>$ such that for any world $w_{0}$, context $c$, interval $t_{0}$, and characteristic function $k$ of a set of times, 【DEFAULT $\mathbb{1}_{w 0, c}(k)\left(t_{0}\right)$ is true iff there is a time $t_{1}$ that abuts $t_{0}$ such that in every $w \in \operatorname{Inr} r\left(\left\langle w_{0}, t_{1}\right\rangle\right)$, there is some time $t \subset t_{0}$ such that $k(t)=1$. For any intervals $t_{1}$ and $t_{2}, t_{1}$ abuts $t_{2}$ iff $t_{1} \cup t_{2}$ is an interval and $t_{1}<t_{2}$. 
(33) Syntax: [ $p$ [before $q]]$ (where $p$ and $q$ are past tense sentences) is analyzed as PAST $\left[p^{\prime} \text { [before } q^{\prime}\right]^{10}$

Translation:

1. before $\Rightarrow \lambda Q_{t} \lambda P_{t} \lambda t \exists t_{2}\left[t_{2}<t \wedge t_{2} \subset t_{R} \wedge P_{t}\left(t_{2}\right) \wedge \operatorname{DEFAULT}\left(Q_{t}\right)\left(t_{R}\right) \wedge\right.$

$\left.\forall t_{1}\left[Q_{t}\left(t_{1}\right) \rightarrow t_{2}<t_{1}\right]\right]$

2. $\quad \mathrm{q}^{\prime} \Rightarrow \lambda t\left[q^{\prime}(t)\right]$

3. $\mathrm{p}^{\prime} \Rightarrow \lambda t\left[p^{\prime}(t)\right]$

4. before $\mathrm{q}^{\prime} \Rightarrow \lambda P_{t} \lambda t \exists t_{2}\left[t_{2}<t \wedge t_{2} \subset t_{R} \wedge P_{t}\left(t_{2}\right) \wedge \operatorname{DEFAULT}\left(q^{\prime}\right)\left(t_{R}\right) \wedge\right.$ $\left.\forall t_{1}\left[q^{\prime}\left(t_{1}\right) \rightarrow t_{2}<t_{1}\right]\right]$

5. $\mathrm{p}^{\prime}$ before $\mathrm{q}^{\prime} \Rightarrow \lambda t \exists t_{2}\left[t_{2}<t \wedge t_{2} \subset t_{R} \wedge p^{\prime}\left(t_{2}\right) \wedge \operatorname{DEFAULT}\left(q^{\prime}\right)\left(t_{R}\right) \wedge\right.$ $\left.\forall t_{1}\left[q^{\prime}\left(t_{1}\right) \rightarrow t_{2}<t_{1}\right]\right]$

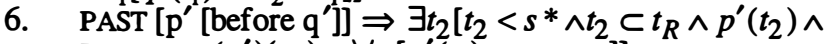
$\left.\operatorname{DEFAULT}\left(q^{\prime}\right)\left(t_{R}\right) \wedge \forall t_{1}\left[q^{\prime}\left(t_{1}\right) \rightarrow t_{2}<t_{1}\right]\right]$

Here, $p^{\prime}$ and $q^{\prime}$ are temporal abstracts that denote the relevant sets of times. $p^{\prime}(t)$ reads ' $p$ ' is true at $t$ '. As mentioned above, the clause DEFAULT $(k)\left(t_{R}\right)$ is officially a presupposition associated with any before-clause. At this point, let us examine whether my proposal predicts that a before-clause is a downward-entailing context. Let us reconsider (34a-b) (presented earlier as (11b)) and see if (34a) entails (34b).

a. John left before Mary or Sue left.
b. John left before Mary left.

The two sentences given in $(34 a-b)$ translate as in (35a-b), respectively, according to my proposal.

$$
\begin{array}{ll}
\text { a. } & \exists t_{2}\left[t_{2}<s^{*} \wedge t_{2} \subset t_{R} \wedge \text { John leaves at } t_{2} \wedge \text { DEFAULT }(\lambda t[\text { Mary or Sue }\right. \\
\text { leaves at } \left.t])\left(t_{R}\right) \wedge \forall t_{1}\left[\text { Mary or Sue leaves at } t_{1} \rightarrow t_{2}<t_{1}\right]\right] \\
\text { b. } \quad \exists t_{2}\left[t_{2}<s^{*} \wedge t_{2} \subset t_{R} \wedge \text { John leaves at } t_{2} \wedge\right. \text { DEFAULT } \\
& \left.(\lambda t[\text { Mary leaves at } t])\left(t_{R}\right) \wedge \forall t_{1}\left[\text { Mary leaves at } t_{1} \rightarrow t_{2}<t_{1}\right]\right]
\end{array}
$$

I assume that the same reference time is used for the evaluation of the two sentences, which is a natural assumption. This is because the entailment relation can only make sense when they are used in the same context, and, therefore, the reference time is also the same interval. Moreover, this interval must be one during which Sue's leaving as well as Mary's leaving are very likely. For example, we can think of the time of a party where both Mary and Sue are present. Thus, for (34a) and (34b) to be comparable, the same presupposition must be shared by them. This means that the sub-formulas that involve DEFAULT in $(35 a-b)$ must be true before we can begin to compare the two sentences. On these assumptions, we can say that my proposal preserves one of the virtues of Anscombe's analysis, namely that a before-clause is a downward-entailing context.

\section{Before and Adverbs of Quantification}

Let us now turn to sentences that involve both a before-clause and an adverb of quantification. For the sake of exposition, let us start with relatively simple examples and try to account for them on the assumption that a beforeclause is entailed by the entire sentence in which it is embedded. Partee (1984:273) considers example (36a) and shows that its rendition given in (36b) incorrectly predicts that John lights up a cigarette at all times before each phone call. However, if we adopted (36c) instead, we would also predict incorrectly that 
one event of John's lighting up a cigarette that precedes all of John's phone calls would be sufficient to make (36a) true.
a. Before John makes a phone call, he always lights up a cigarette.
b. $\forall t \forall t^{\prime}\left[\left[t^{\prime}<t \wedge\right.\right.$ John makes a phone call at $\left.t\right] \rightarrow$ John lights up a cigarette at $t]$
c. $\quad \forall t\left[\right.$ John makes a phone call at $t \rightarrow \exists t^{\prime}\left[t^{\prime}<t \wedge\right.$ John lights up a cigarette at $\left.\left.t^{\prime}\right]\right]$

The problem is avoided if we assume that always quantifies over a preselected set of non-overlapping intervals. This is based upon our intuition that when we use always, we think of all the relevant situations that fit some description and are disjoint from one another. I simply assume that in the case of temporal examples, the domain of quantification for an adverb of quantification is a set of mutually disjoint intervals. Let us use $I_{c}$ to refer to the set of contextually determined intervals for context $c$ and define it as in (37).

(37) For any context $c$, the domain of quantification for an adverb of temporal quantification is a set of intervals $I_{c}$ such that for any $t, t^{\prime} \in I_{c}, t \cap t^{\prime}=\varnothing$

Following (37), (36a) is analyzed as follows:

$\forall t \forall t^{\prime \prime}\left[t \in I_{c} \wedge t^{\prime \prime} \subset t \wedge\right.$ John makes a phone call at $t^{\prime \prime} \rightarrow \exists t^{\prime}\left[t^{\prime}<t^{\prime \prime}\right.$ $\wedge t^{\prime} \subset t \wedge$ John lights up a cigarette at $\left.\left.t^{\prime}\right]\right]$

Since the set of intervals $I_{c}$ only contains non-overlapping intervals, and since for each case the two relevant events must be located within the given time frame, both of the problems presented above are corrected here.

However, the analysis given in (38) is not valid for non-factual beforeclauses. Thus, we must modify it to accommodate them. The non-factual nature of before-clauses is preserved even when an adverb of quantification is superimposed on the structure. Consider the following example:
John was unhappy and there were many times in his life that he had thought about killing himself. But his wife always came to his rescue before he jumped out of the window.

For the obvious reason, the situations that we must consider are those in which John was suicidal, not those in which John actually killed himself. (39) says that for each such occasion, his wife's coming to his rescue prevented him from committing suicide. I believe that (40) accurately describes the truth conditions for sentences of the form always $p$, before $q$.

$$
\begin{aligned}
& \text { always } p \text {, before } q \text { (where } p \text { and } q \text { are past tense sentences) is true in } w_{0} \text { at } \\
& s^{*} \text { in } c \text { iff }\left\{t \mid t<s^{*} \text { and } t \in I_{c} \text { and DEFAULT }\left(q^{\prime}\right)(t) \text { is true in } w_{0}\right\} \subseteq\{t \\
& \mid t<s^{*} \text { such that } t \in I_{c} \text { and there is a time } t_{3} \subset t \text { such that } p^{\prime} \text { is true at } t_{3} \\
& \text { and every } \left.t_{4} \subseteq t \text { at which } q^{\prime} \text { is true is located after } t_{3}\right\}
\end{aligned}
$$

Now the question is how to arrive at (40) compositionally. Stump (1985) proposes a theory in which an adverb of quantification takes as its two arguments the translations of the adverbial clause and the main clause, which are temporal abstracts. Consider (41) for example. 
(41) is symbolized as in (42).

\section{ALWAYS ( $\lambda t$ [Mary calls John at $t])(\lambda t[$ John is asleep at $t])$}

Roughly speaking, always $p$, when $q$ is true iff $\left\{t \mid q^{\prime}\right.$ is true at $\left.t\right\} \subseteq\left\{t^{\prime} \mid p^{\prime}\right.$ is true at $t\}$, abstracting away from the semantic contribution of the tense morphemes. However, if the compositional analysis of before given in (33) is correct, (40) cannot be derived in the same way. The reason is that the "nuclear scope" of always given above in the form of a set of intervals (i.e., $\left\{t \mid t<s^{*}\right.$ such that $t \in I_{c}$ and there is a time $t_{3} \subset t$ such that $p^{\prime}$ is true at $t_{3}$ and every $t_{4} \subseteq t$ at which $q^{\prime}$ is true is located after $\left.t_{3}\right\}$ ) makes reference to the times at which the before-clause is true (as well as to the times at which the main clause is true). Thus, we cannot simply take the translation of the before-clause and the translation of the main clause and state the relation between these two sets.

One possible alternative is to look for the source of the domain of quantification for quantificational adverbs elsewhere. This idea seems plausible when we consider examples like the following:

When I go to my office, I always drink coffee before I start doing anything.

The truth conditions of (43) can be described as follows:

(44) $\left\{t \mid t \in I_{c}\right.$ and I am in my office at $\left.t\right\} \subseteq\left\{t \mid t \in I_{c}\right.$ and there is a time $t^{\prime} \subset t$ at which I drink coffee and every time $t^{\prime \prime} \subset t$ at which I do anything is located after $\left.t^{\prime}\right\}$

According to this analysis, the set of times at which the when-clause is true serves as the domain of quantification (or "restrictor") for always, and the set of times at which the rest of the sentence (including the before-clause) is true serves as the "nuclear scope." 11 The problem with this proposal is that it requires the existence of an overt when-clause, which is often missing.

Setting aside the problem of compositionality, we notice one interesting prediction that (40) makes. Consider (43). (40) predicts that if the speaker goes to his office ten times, it is acceptable for him to do something after drinking coffee in seven of the ten visits and not to do anything after drinking coffee in the three others. Although the judgments are subtle, this prediction is also borne out by an example like (45), which is a quantified version of (17).

Whenever John attended a party held at Bill's house, Bill drank a lot and looked as if he was going to get drunk. Since John hates to deal with drunkards, he always left before Bill got drunk.

(45) allows the possibility that in some cases Bill actually got drunk and in other cases he did not. This is precisely what (40) predicts. My informant says that (45) is only marginally acceptable on this interpretation, and this reading is more readily available when the entire discourse is in the present tense. I do not have a good explanation for this observation. The following Japanese sentence is perfectly acceptable and leaves open whether or not Hanako got drunk on each occasion:

Taroo-wa itumo Hanako-ga you mae-ni kaet-ta. Taro-TOP always Hanako-NOM get-drunk-PRES before leave-PAST 'Taro always left before Hanako got drunk.' 
The following English sentences are better examples of non-committal before, according to my informant:

(47) a. I used to go to my office every day. But when I got there, I always fell asleep before I started doing anything.

b. I was often in the parts of the world that were politically unstable. I always left the country before any riot occurred.

(47a) allows the possibility that I fell asleep in my office and ended up doing nothing on some occasions. (47b) makes the same point. The sentence is true even if in some situations no riot occurred after the speaker left the country. Thus, the truth conditions given in (40) receive empirical support. This once again confirms my claim that the interpretation of before due to Anscombe captures the assertion made by any before-clause.

Turning to usually, we notice an interesting point with regard to (48a-b).

a. The object of the game was to prevent the invaders from reaching the player's territory. Since John was a good player, he usually succeeded in destroying the invaders before they reached his territory.

b. John often borrowed books from the university library. He usually returned them before he was fined.

Intuitively, (48a) is true iff in most of the situations in which the invaders were approaching his territory, he destroyed them, thereby preventing them from reaching it. But in a small number of cases, he failed to destroy them, and they did reach his territory. Thus, this default interpretation of (48a) shows that the beforeclause describes factual events and non-factual events at the same time. What this tells us conclusively is that Anscombe's analysis is correct. By leaving open whether the before-clause is true or not for each case, we can make the right predictions about the truth conditions for (48a). (48b) makes the same point. Let me provide the following truth conditions for sentences involving usually and before:

Usually $p$, before $q$ (where $p$ and $q$ are sentences in the past tense) is true in $w_{0}$ at $s^{*}$ in $c$ iff for most $t_{1}$ such that $t_{1}<s^{*}, t_{1} \in I_{c}$ and

【DEFAULT $\left(\mathrm{q}^{\prime}\right) \rrbracket_{g, c}\left(t_{1}\right)=1$, there is a time $t_{2} \subset t_{1}$ at which $p^{\prime}$ is true and every time $t_{3} \subset t_{1}$ at which $q^{\prime}$ is true is located after $t_{2}$.

On its default reading, (48a) pragmatically presupposes that destroying invaders generally prevent them from reaching the player's territory. In most cases, John destroys the invaders, and this pragmatically entails that they do not reach John's territory. In the small number of cases where John fails to do so, we infer that the invaders do reach John's territory because this is the default outcome and, moreover, the player is the only person who can prevent this consequence in a game situation. This is predicted from the above truth conditions combined with the assumed pragmatic presupposition.

In order to deal with quantificational examples in a natural way, I adopt Rooth's (1985) domain selection theory. 12 Rooth discusses how adverbs of quantification interact with when-clauses. According to this theory, unlike Stump's (1985) theory, the restrictive clause for always does not come directly from the content of the temporal adverbial clause such as a before-clause. Rather the relevant information is derived from the focus structure of the entire sentence. Although the treatment of before-clauses is more complicated than when-clauses, 
Rooth's proposal about adverbs of quantification can be extended straightforwardly to before cases. On the basis of (40), the truth conditions for sentences that involve a before-clause and always (as an instance of an adverb of quantification) are stated schematically as follows:

(50) always $p$ before $q$ is true in $w_{0}$ at the speech time $s^{*}$ in $c$ iff

【ALWAYS $\left(P_{t}\right)\left(\lambda t\left[t \in I_{c} \wedge t<s^{*} \wedge \operatorname{DEFAULT}\left(q^{\prime}\right)(t) \wedge \exists t_{2}\left[t_{2} \subset t \wedge p_{F}^{\prime}\left(t_{2}\right) \wedge\right.\right.\right.$ $\left.\left.\left.\forall t_{3}\left[\left[q^{\prime}\left(t_{3}\right) \wedge t_{3} \subset t\right] \rightarrow t_{2}<t_{3}\right]\right]\right]\right) \mathbb{I}_{w_{0}, c}=1$. For any $k_{1}, k_{2} \in D_{<i, \triangleright,}$

【ALWAYS $\left(k_{1}\right)\left(k_{2}\right)=1$ iff $\left\{t \mid k_{1}(t)=1\right\} \subseteq\left\{t \mid k_{2}(t)=1\right\}$. ( $D_{a}$ for any type $a$ is the set of all possible denotations of type $a$. ALWAYS is a constant of

type $\langle<i, t>,\langle<i, t>, t>>$.)

$P_{t}$ in (50) is a free variable for sets of times. Assuming that the main clause is focused, the "domain of quantification" for always in (50) is obtained from the translation of the non-quantified sentence given in (33) via the following computation (Rooth 1985:173):

$$
\begin{array}{ll}
\text { a. } & \left\{\lambda t \left[t \in I_{c} \wedge t<s^{*} \wedge \operatorname{DEFAULT}\left(q^{\prime}\right)(t) \wedge \exists t_{2}\left[t _ { 2 } \subset t \wedge r ( t _ { 2 } ) \wedge \forall t _ { 3 } \left[\left[q^{\prime}\left(t_{3}\right)\right.\right.\right.\right.\right. \\
& \left.\left.\left.\left.\left.\wedge t_{3} \subset t\right] \rightarrow t_{2}<t_{3}\right]\right]\right] \mid r \in D_{<i, t>}\right\} \text { (where } s^{*} \text { denotes the speech time) } \\
\text { b } & \cup\left\{\lambda t \left[t \in I _ { c } \wedge t < s ^ { * } \wedge \text { DEFAULT } ( q ^ { \prime } ) ( t ) \wedge \exists t _ { 2 } \left[t_{2} \subset t \wedge r\left(t_{2}\right) \wedge\right.\right.\right. \\
& \left.\left.\left.\forall t_{3}\left[\left[q^{\prime}\left(t_{3}\right) \wedge t_{3} \subset t\right] \rightarrow t_{2}<t_{3}\right]\right]\right] \mid r \in D_{<i, t>}\right\}
\end{array}
$$

(5ं1a) represents the p-set of any sentence of the form $p_{F}$ before $q$, where the subscripted $F$ indicates a focused constituent. In order to derive the set of times that is appropriate for restricting the domain of quantification for always, the union operation on this p-set is required as described in (51b). I follow the strategy adopted by Rooth to arrive at the result of this operation. If we posit a constant of type $\langle i, t\rangle\left(c_{1,<i, t\rangle}\right)$ that denotes the set of all times, (52) denotes a member of the family of sets given in (51a).

$$
\begin{aligned}
& \lambda t\left[t \in I _ { c } \wedge t < s ^ { * } \wedge \text { DEFAULT } ( q ^ { \prime } ) ( t ) \wedge \exists t _ { 2 } \left[t_{2} \subset t \wedge c_{1,<i, t>}\left(t_{2}\right)\right.\right. \\
& \left.\left.\wedge \forall t_{3}\left[\left[q^{\prime}\left(t_{3}\right) \wedge t_{3} \subset t\right] \rightarrow t_{2}<t_{3}\right]\right]\right]
\end{aligned}
$$

Since $c_{1,<i, t>}\left(t_{2}\right)$ is true for any value of $t_{2}$, the denotation of (52) is the most inclusive set and is equivalent to (51b). Moreover, (53a) is guaranteed to be true for any value of $t$ because $t_{3} \subset t$ reads ' $t_{3}$ is a non-initial subinterval of $t$ ' and, therefore, there is always some time earlier than $t_{3}$ and is part of $t .^{\prime}{ }^{13}$ Thus, (52) is semantically equivalent to (53b).

$$
\begin{aligned}
& \text { a. } \exists t_{2}\left[t_{2} \subset t \wedge c_{1,<i, t>}\left(t_{2}\right) \wedge \forall t_{3}\left[\left[q^{\prime}\left(t_{3}\right) \wedge t_{3} \subset t\right] \rightarrow t_{2}<t_{3}\right]\right] \\
& \text { b. } \quad \lambda t\left[t \in I_{c} \wedge t<s^{*} \wedge \operatorname{DEFAULT}\left(q^{\prime}\right)(t)\right]
\end{aligned}
$$

Thus, the truth conditions for sentences of the form always $p$, before $q$ are given as (54a), which is reduced to (54b) after removing the redundant materials in the "nuclear scope" of always.

$$
\begin{array}{ll}
\text { a. } & \text { ALWAYS }\left(\lambda t\left[t \in I_{c} \wedge t<s * \wedge \operatorname{DEFAULT}\left(q^{\prime}\right)(t)\right]\right)\left(\lambda t \left[t \in I_{c} \wedge t<s * \wedge\right.\right. \\
& \text { DEFAULT }\left(q^{\prime}\right)(t) \wedge \exists t_{2}\left[t_{2} \subset t \wedge p_{F}^{\prime}\left(t_{2}\right)\right. \\
& \left.\left.\wedge \forall t_{3}\left[\left[q^{\prime}\left(t_{3}\right) \wedge t_{3} \subset t\right] \rightarrow t_{2}<t_{3}\right]\right]\right] \\
\text { b. } & \text { ALWAYS }\left(\lambda t\left[t \in I_{c} \wedge t<s^{*} \wedge \operatorname{DEFAULT}\left(q^{\prime}\right)(t)\right]\right)\left(\lambda t \left[t \in I_{c} \wedge\right.\right. \\
& \left.\left.\exists t_{2}\left[t_{2} \subset t \wedge p_{F}^{\prime}\left(t_{2}\right) \wedge \forall t_{3}\left[\left[q^{\prime}\left(t_{3}\right) \wedge t_{3} \subset t\right] \rightarrow t_{2}<t_{3}\right]\right]\right]\right)
\end{array}
$$

(54b) says "every contextually defined past interval within which $q^{\prime}$ occurs as a 
default is a time within which $p^{\prime}$ occurs before $q^{\prime}$ does." This accords with the native speaker's intuitions about English sentences that involve before-clauses.

\section{Distinct Readings of Before-Clauses and Pragmatic Presuppositions}

My general proposal about the semantics of before is that a unified account based upon Anscombe's proposal is possible. This is similar to Heinämäki's $(1972,1974)$ position. In order to defend this position, we must assume that pragmatic presuppositions are responsible for a variety of interpretations associated with before-clauses. At this point, let me make clear my theoretical position with regard to presuppositions and look at some important data from this perspective. I assume with Stalnaker $(1972,1974,1978)$ that a proposition is presupposed iff it is entailed by the "context set," which is a set of possible worlds. 14

First, before requires the reference time to be an interval during which a before-clause event is likely to obtain. As mentioned above, I take this to be a presuppositional meaning generally associated with before.

Second, causal relations between main clause events and before-clause events affect the interpretation of before-clauses. Let us reconsider (55a) (cited earlier as (5)), which receives two distinct interpretations depending upon the relation between the before-clause and the main clause.
a. John pushed the button before the fire started.
b. The button is pushed. $\Rightarrow$ A fire starts.
c. The button is pushed. $\Rightarrow \mathrm{A}$ fire is prevented.

Assume that (55b) and (55c) are interpreted in terms of Lewis's (1973) proposal for counterfactual conditionals. Suppose that (55a) is uttered in two different contexts. In context $c_{1},(55 \mathrm{~b})$ is part of the common ground, whereas in context $c_{2}$, (55c) is part of the common ground. In both contexts, the reference time must be an interval during which the fire is likely to start. In context $c_{1}$, the hearer infers from (55a) that the fire actually started. On the other hand, in context $c_{2}$, it is assumed that the fire was prevented due to the presupposition given in (55c). This explains the different inferences in the two cases. This account extends straightforwardly to quantificational examples. For example, (56) allows the same type of ambiguity.

John always pushed the button before the fire started.

Note that (55) is not vague in the way that $(47 a-b)$ are. Once the context is fixed, the interpretation is either that the fire started on all occasions or that the fire was prevented on all occasions. This is exactly what my system predicts.

What if there is no causal connection between the two clauses in question? Because of the way the semantics of before-clauses is defined (see (54)), it is expected that there is a before-clause event within the reference time. However, there is no guarantee that this would happen because it is always possible that an independent event not described by the main clause prevents the occurrence of a before-clause event. This reasoning leads to the right interpretation of (57), cited earlier as (15e).

I left the country before anything happened.

Assume that the speaker was just a powerless foreigner and had no influence on whatever was about to take place. Thus, his leaving did not directly cause any important events there. Pragmatic presuppositions hence do not provide 
information as to whether anything happened after the speaker left, leaving the impression that the truth value of the before-clause is undetermined.

Other pragmatic presuppositions influence the ways in which beforeclauses are interpreted. For example, in (58), the before-clause is clearly part of the common ground.

(58) John did help Mary in the end. But he made it clear that he was doing her a big favor before he did so.

Similarly, it is possible that the negation of the before-clause is part of the common ground as in (59).

(59) John did not commit suicide. His wife came to his rescue before he jumped out of the window.

The truth of John did not commit suicide is compatible with the truth conditions of the second sentence in (59), and this is responsible for the impression that the negation of the before-clause is entailed by the entire sentence.

Finally, let me make a brief remark on preposed before-clauses. Knud Lambrecht (personal communication) points out that preposed before-clauses are always factual. Unlike (55), (60) is not ambiguous.

(60) Before the fire started, John pushed the button.

In Japanese, mae-ni-clauses are always preposed, but topicalized mae-ni-clauses behave like preposed before-clauses in English in that they are necessarily factual. Note that (61) is anomalous (cf. (7a)). 15,16

(61) \# Taroo-wa Mago-no kao-o miru mae-ni-wa sin-da. Taro-TOP grandchildren-GEN face-ACC see-PRES before-TOP die-PAST [Intended] 'Taro died before he saw his grandchildren.'

As far as I can see, the status of (61) is very similar to that of English sentence (62), which involves a preposed before-clause.

(62) \# Before John saw his grandchildren, he died.

I contend that the above facts are accounted for if we assume that preposed before-clauses in English and topicalized mae-ni-clauses in Japanese are presupposed. This is no explanation, but it is a plausible assumption because topicalized constituents are often claimed to convey "old information" (e.g., Kuno $1973)$, which is clearly related to the notion of pragmatic presupposition. The similarity between (61) and (62) is striking enough for us to assume that preposing a before-clause and topicalizing a mae-ni-clause have the same semantic effect. Thus, I argue that preposed before-clauses in English and topicalized mae-ni-clauses in Japanese carry with them an existential presupposition.

Existential Presupposition of Preposed before:

before $q, p$ (or $q$-mae-ni-wa, $p$ in Japanese) presupposes $\exists t\left[t \subseteq t_{R} \wedge q^{\prime}(t)\right]$

Since a sentence of the form before $q$ asserts that no before-clause event obtains before the main clause event, we can conclude that a before-clause event obtains after the main clause event. 


\section{Concluding Remarks}

In this paper, I have discussed the interaction between non-factual before and adverbs of quantification. My analysis of before is based upon Anscombe's (1964) and is supplemented by some auxiliary proposals. First, a modal-temporal analysis of the pragmatic presupposition associated with before specifies the relevant interval within which the occurrence of a main clause event is likely. Second, the interaction between before and adverbs of quantification is explained in terms of Rooth's domain selection theory. Third, the distinct interpretations associated with factual and non-factual before-clauses are attributed to pragmatic presuppositions. Our next task will be to provide a formal treatment of discourse presuppositions and their interactions with various interpretations of beforeclauses, but this would require another paper.

\section{Endnotes}

* I thank Sharon Hargus, Heles Contreras, Craige Roberts, Henriëtte de Swart, Bill Ladusaw, Michael Johnston, Giulia Centineo, Chris Kennedy, Amim von Stechow, Greg Carlson, David Dowty, Lee Baker, Ray Jackendoff, Friederike Moltmann, Knud Lambrecht, Margaret Campos, Ikumi Imani, Heles Contreras, Antxon Olarrea, and participants of SALT5 for discussions, suggestions, examples, native intuitions, etc. regarding the material presented here. I apologize for those who are inadvertently omitted. I alone am responsible for any errors.

1 Heinämäki (1974) uses the term "non-committal" for this type of reading, whereas Sánchez-Valencia et al. (1994) employ the term "non-veridical."

2 Strictly speaking, the temporal locations of the events in (3) must be constrained by contextually supplied reference times. This point will be discussed in Section 3. See Ogihara (in press) for details.

3 Ogihara (1994) presents a sequence-of-tense analysis of tense morphemes in Japanese and English temporal adverbial clauses, assuming that they are factual clauses.

4 Anscombe (1964:10-11) herself makes a negative remark on this proposal, which involves quantification over times. However, since the basic idea originates in Anscombe's work, I will refer to it as Anscombe's proposal in the rest of the paper.

5 This account tacitly assumes that stative sentences have the so-called subinterval property (Bennett and Partee 1972, Dowty 1979).

6 I will discuss the problem associated with repeated occurrences of before-clause events in Section 3.

7 If we adopt the truth conditions given in (10), then a question immediately arises as to how the observed difference between factual and non-factual cases should be accounted for. This topic will be discussed in sections 3 through 5 .

8 See Sánchez Valencia et al. (1994) for the relation between veridicality and downward-entailingness.

9 uti literally means 'inside' or 'within'.

10 This is based upon a sequence-of-tense analysis of tense morphemes in embedded structures. In this particular case, the past tense morpheme in the before-clause is analyzed as semantically empty. See Ogihara (in press).

11 I use this term only for expository purposes. It is due to Heim (1982).

12 Johnston (1994) criticizes Rooth's theory of focus regarding temporal adverbial clauses. I acquired a copy of this work when I was completing this paper and hence cannot respond to it in this paper because of time constraints.

13 See example (30). 
14 The context set can be derived by the following operation: $\cup\{p \mid p$ is a proposition that is taken for granted by the participants of the conversation $\}. p$ is presupposed in context $c$ iff $p$ is true in every world in the context set.

15 I thank Ikumi Imani (personal communication) for calling my attention to topicalized mae-ni ('before')-clauses in Japanese.

16 Note that (i) is perfectly acceptable.

(i) Taroo-wa Kyoto-ni kuru mae(-ni)-wa Tokyo-ni sundei-ta Taro-TOP Kyoto-DAT come-PRES before-TOP TOKYO-at live-PAST 'Taro lived in Tokyo before he came to Kyoto.'

\section{References}

Anscombe, Gertrude Elizabeth Margaret. (1964) "Before and After," The Philosophical Review 73, 3-24.

Dowty, David. (1979) Word Meaning and Montague Grammar: The Semantics of Verbs and Times in Generative Semantics and in Montague's PTQ, D. Reidel, Dordrecht.

Heim, Irene. (1982) The Semantics of Definite and Indefinite Noun Phrases, Ph. D. dissertation, University of Massachusetts at Amherst.

Heinämäki, Orvokki. (1972) "Before," Papers from the Eighth Regional Meeting of the Chicago Linguistic Society, Chicago Linguistic Society, 139-151.

Heinämäki, Orvokki. (1974) Semantics of English Temporal Connectives, Ph.D. dissertation, University of Texas at Austin.

Johnston, Michael. (1994) The Syntax and Semantics of Adverbial Adjuncts, Ph. D. dissertation, University of Califomia at Santa Cruz.

Kuno, Susumu. (1973) The Structure of the Japanese Language, The MIT Press, Cambridge, Massachusetts.

Ladusaw, William. (1979) Polarity Sensitivity as Inherent Scope Relations, Ph.D. dissertation, University of Texas at Austin.

Landman, Fred. (1991) Structures for Semantics, Kluwer, Dordrecht.

Lewis, David. (1973) Counterfactuals, Harvard University Press, Cambridge, Massachusetts.

Nakau, Minoru. (1976) “Tense, Aspect, and Modality," in Masayoshi Shibatani (ed.), Syntax and Semantics 5, Japanese Generative Grammar, Academic Press, New York.

Ogihara, Toshiyuki. (1994) "Adverbs of Quantification and Sequence-of-Tense Phenomena," Proceedings from Semantics and Linguistic Theory IV, Mandy Harvey and Lynn Santelmann (eds.), DMLL Publications, Cornell University, 251-267.

Ogihara, Toshiyuki. (in press) "The semantics of Tense in Embedded Clauses," Linguistic Inquiry 26, Number 4.

Ota, Akira. (1973) "Tense Correlations in English and Japanese," Studies in English Linguistics 2, 108-21.

Partee, Barbara Hall. (1984) "Nominal and Temporal Anaphora," Linguistics and Philosophy 7, 243-286.

Reichenbach, Hans. (1947) Elements of Symbolic Logic, Macmillan, New York.

Rooth, Mats. (1985) Association with Focus, Ph.D. dissertation, University of Massachusetts at Amherst.

Sánchez-Valencia, Víctor, Ton van der Wouden, and Frans Zwarts. (1994) "Polarity, Veridicality, and Temporal Connectives," Proceedings of the Ninth Amsterdam Colloquium, December 14-17,1993, Part 3, Paul 
Dekker and Martin Stokhof (eds.), ILLC, University of Amsterdam, 587606.

Stalnaker, Robert. (1972) "Pragmatics," in Herman and Davidson (eds.), Semantics of Natural Language, 380-397, D. Reidel, Dordrecht.

Stalnaker, Robert. (1974) "Pragmatic Presuppositions," in Milton Munitz and Peter Unger (eds.), Semantics and Philosophy, New York University Press, New York, 197-213.

Stalnaker, Robert. (1978) "Assertion," in P. Cole. (ed.) Pragmatics, Syntax and Semantics, Vol. 9. Academic Press, New York, 315-332.

Stump, Gregory. (1985) The Semantic Variability of Absolute Constructions, Kluwer, Dordrecht.

Department of Linguistics

University of Washington

Box 354340

Seattle, WA $98195-4340$

ogihara@u.washington.edu

http://weber.u.washington.edu/ ogihara 